\title{
A Soft Approach to Estimate Woody Volume of a Live Tree
}

\author{
NIKITA SINGLA* and DERMINDER SINGH
}

School of Electrical Engg. \& IT COAE\&T, PAU Ludhiana India.

\begin{abstract}
Tree volume is one of the oldest areas of interest and is a crucial task in tree management system. Estimating the woody volume of a live tree is important for economic, scientific purposes and provides a tool to researcher/grower. It provides the useful information about the commercial value of wood to the potential buyer/seller. However, manual methods are being used largely to calculate woody volume of a tree. These methods are based on different log rules, cumbersome and laborious. The present work proposed a digital image processing technique to estimate the woody volume of a live tree. The developed program successfully determines the woody volume of standing tree trunk with MATLAB image processing techniques. In this method three parameters an individual tree were extracted from digital images of the tree. Calibration factor was also calculated to make the method independent of camera distance from the tree. The method was tested on several samples of trees and compared to experimental results. The soft approach generates information about height, diameter and volume of the tree. The percentage error of height, diameter at breast height and volume of standing tree by proposed method and experimental results was found to be less than $6.65 \%$.
\end{abstract}

\section{Introduction}

Wood is essential as a construction material, pulp and paper manufacture, fuel and energy and for a wide variety of other uses. Woody volume of tree is a significant parameter in tree management system. It is most widely used measure of wood quantity and is usually estimated for the assessment of economic /commercial utilization potential. The wood volume of a tree includes trunk, branches and roots. For standing trees, above ground volume prediction is generally based on trunk wood volume, but may include branch volume for broad-leaved tree species.

Estimating the woody volume of live tree usually requires measurement of trunk diameter at breast height and height of the trunk. Number of methods has been developed for this purpose such as: biltmore stick and volume table that are conventional ways for estimating the height and

CONTACT Nikita Singla nikita-seeit@ pau.edu $\mathbf{9}$ School of Electrical Engg. \& IT COAE\&T, PAU Ludhiana India. (C) 2017 The Author(s). Published by Enviro Research Publishers

This is an $\widehat{C}$ Open Access article licensed under a Creative Commons Attribution-NonCommercial-ShareAlike 4.0 International License (https://creativecommons.org/licenses/by-nc-sa/4.0/ ), which permits unrestricted NonCommercial use, distribution, and reproduction in any medium, provided the original work is properly cited.

To link to this article: http://dx.doi.org/10.13005/ojcst/10.03.10 
diameter of standing trees. But these methods are based on different log rules, cumbersome and laborious. Also the estimation of standing tree volume operation is considered a difficult task as ground survey is required 5 .

Tree height and diameter are important parameters for calculation of wood volume of a standing tree. The economic value of tree is mostly determined by these parameters, however the fast calculation of these parameters are difficult without using specified instruments and human expertise. There are many specified and scientific instruments like abneys level, wooden scale etc which are available in market for height and diameter measurement instead of this the manual methods (wooden stick, measuring tape etc) are still in use. These methods although severs the purpose but lacks with the accuracy, reliability and time consuming. An attempt to make a semi automate system will provide us more accurate result in very short time. Hence provides a non destructive method of measurement using image processing technique.

This approach provides an effective tool to estimate the volume of standing tree of varying sizes. In this the image is converted into digital form and carry out some operations on it, in order to get an enhanced image, remove defects such as geometric distortion, improper focus, camera motion, non-uniform lighting and extract some valuable information from it. It is kind of signal dispensation in which we take image as input, like video frame or photograph and output can be image or characteristics related with the input image.

Few research papers have been published in the area of standing tree woody volume calculation that is based on applications of image processing. Many algorithms have been developed for this purpose but all these researches and algorithms have their own advantages and disadvantages. This paper represents an approach for determining the woody volume of a standing tree based on image processing techniques that are easy and inexpensive. Hence, the developed system will ease the human efforts.

\section{Material and Methodology Material}

Several samples of tree were used for determining the woody volume of standing tree. The images of tree were captured with a Sony digital camera model number dsc-wx50. A square wooden frame of known dimension was used as a calibration factor. Manual instruments like vernier caliper and clinometer were used to calculate the height and diameter of trees for result validation.

\section{Methodology}

Figure 1 defines the various phases involved in complete development of this application.

\section{Image Preprocessing}

Preprocessing is considered as an essential step for enhances the image features and to restrain the unnecessary distortions of the captured image. It is a general name for process involved with images at base point of abstraction. In order to obtain a newly bright pixel value in the resultant image, the preprocessing techniques uses a little neighborhood of a pixel in an image. Gaussian filter is also produced to reduce the noise in the image.

\section{Image Marking}

Initially the captured image is marked with the red, blue and green colors. Red color circles were fixed (one circle at the root of the tree and other is at the some distance high from the root) on the tree image to calculate the height. Blue color mark was used to calculate the diameter (DBH) and Green color mark was used to calculate the calibration factor. The calibration factor was used to eliminate the effect of distance in the tree images.

\section{Extracting the Red Points}

To extract the red marker points on the tree image, firstly the threshold value is set for each color frame. Maximum threshold value is 255 . To extract the red color from the image the threshold value of red color frame is high as compare to the threshold value of blue and green color. It will extract the red circle from the tree image and the resultant image will show only the two red circles on the screen. Distance between these two circles gives the height of the 
tree. Also if the resultant image has holes that can also fill by using the function imfill.

\section{Extracting the Blue Point}

To extract the blue marker point on the tree, the threshold value for blue color frame is set high and low threshold value for the rest two colors. The maximum threshold value is 255 same as in red color extraction. It will extract the blue color frame from the tree image and the resultant image will show only the blue color frame on the screen. The number of pixels calculated in the blue color frame will give the width (diameter) of the tree. Holes in

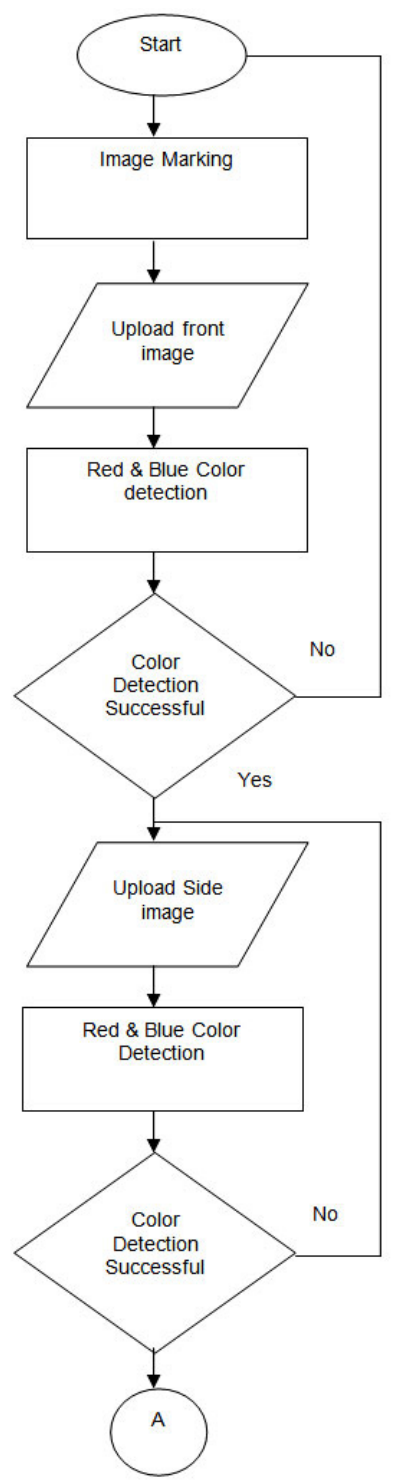

the resultant image can also fill with the extracted color by using the function imfill.

\section{Calculate the Calibration Factor}

A square wooden frame of known dimensions is used as a calibration factor. In the tree image the wooden frame is filled with green color. To extract the green marker point on the tree image, the color frames were created in the same way as for red and blue color. The green color frame was set with high threshold value and rest two colors low were set with low threshold value. Maximum threshold value is same as in red and blue color extraction.

\section{Fig. 1: Flow Chart of Proposed System}

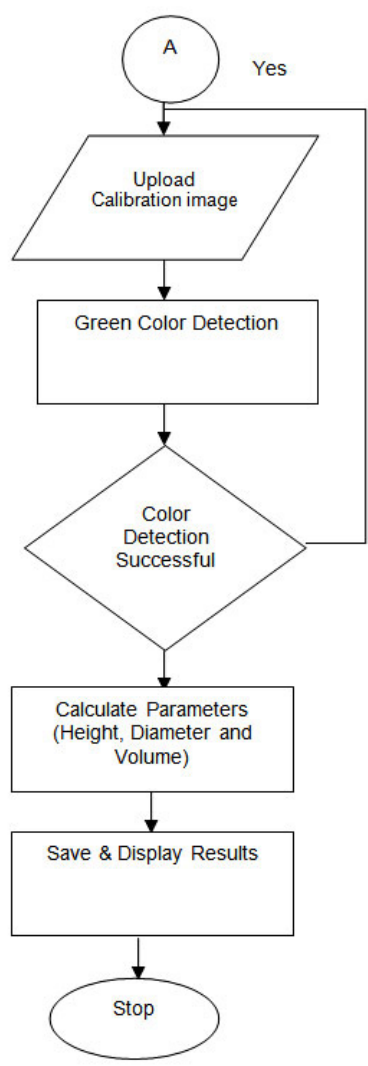


Similarly the resultant image holes were fill with the extracted color by using the function imfill. The resultant image will separated only the green marks from the image.

\section{Parameter Extraction}

Firstly, the number of pixels was calculated in the 32 by 32 inches frame (blue color) for calibration factor. As the frame is of square type the length and width of the frame is same. As the number of pixel were calculated in term of inches. But the results are required in terms of meters. Therefore the area of one pixel in meters is calculated by doing the required calculations. Then this result (area of one pixel in meters) is used for calculating the total body mass, height and diameter of the tree in meters. The advantage of using the frame as a calibration factor is to eliminate the effect of distance in the tree images. The tree images were taken from two directions, one from the front side and second from the perpendicular side therefore for every tree three images (one for front side, second from perpendicular side and third for calibration factor) are processed for calculating the final results. Results have been processed after taking the average values of all parameters. The following parameters are calculated from the image of the tree:

i. Height: It is the distance between the centroid of two red color circles. Then by applying the distance formula on the centroids the height of the tree is calculated. As we have the two image of every tree i.e. one from front direction and other from perpendicular direction we calculate height from both sides then take the average value.

ii. Diameter: It is calculated from the number of pixel in the blue color frame. Similarly the diameter is also calculated from both sides of the tree and then average value is used in the final results.

iii. Volume: From the tree height and diameter volume is calculated. By doing the simple multiplication of height and diameter values the total volume of the tree is calculated.

\section{Results And Discussions}

a. Three parameters of standing trees i.e. height, diameter (DBH) and volume of several samples were calculated by proposed method and manual method. The results of six samples of trees are given in table I. The error rate of calculating different parameters of trees between proposed method and experimental analysis is found to be less than $6.65 \%$.

b. The error between the value of height obtained from the application and manual method for poplar and teak trees is $0.27 \%$, $0.53 \%$ and $4.9 \%$ respectively shown in table II.

c. The error between the value of diameter obtained from the application and manual method for poplar and teak trees is $2.72 \%$, $4.13 \%$ and $5.24 \%$ respectively sown in table III.

d. Comparison of standing tree height calculated by propose method and manual methods is illustrate in figure 2.

e. Comparison of standing tree diameter at breast height calculated by proposed method and manual method is illustrated in figure 3 .

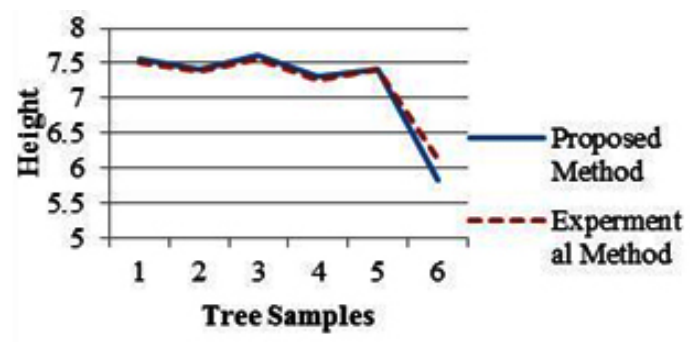

Fig. 2: Comparison of tree height (m) calculated by proposed method and manual method

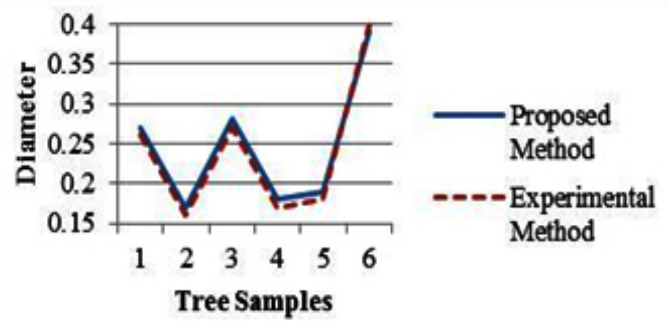

Fig. 3: Comparison of tree Diameter (m) calculated by proposed method and manual method 
Table 1: Standing trees volume measurement results in meters by proposed method

\begin{tabular}{lccc}
\hline $\begin{array}{l}\text { Tested } \\
\text { Trees }\end{array}$ & $\begin{array}{c}\text { Height } \\
(\mathbf{m})\end{array}$ & $\begin{array}{c}\text { Diameter } \\
(\mathbf{m})\end{array}$ & $\begin{array}{c}\text { Volume } \\
(\mathbf{m} 3)\end{array}$ \\
\hline Tree 1 & 7.56 & 0.27 & 0.43 \\
Tree 2 & 7.41 & 0.17 & 0.16 \\
Tree 3 & 7.6 & 0.28 & 0.46 \\
Tree 4 & 7.3 & 0.18 & 0.19 \\
Tree 5 & 7.42 & 0.19 & 0.21 \\
Tree 6 (Teak) & 5.83 & 0.39 & 0.67 \\
\hline
\end{tabular}

Table 3: Contrast table for standing tree Diameter (DBH) with two different methods

\begin{tabular}{llll}
\hline $\begin{array}{l}\text { Tested } \\
\text { Trees }\end{array}$ & $\begin{array}{l}\text { Diameter }(\mathbf{m}) \\
\text { (Proposed } \\
\text { Method) }\end{array}$ & $\begin{array}{l}\text { Diameter }(\mathbf{m}) \\
\text { (Experimental } \\
\text { Values) }\end{array}$ & $\begin{array}{l}\text { Percentage } \\
\text { Error }\end{array}$ \\
\hline & & & \\
Tree 1 & 0.27 & 0.26 & $5.24 \%$ \\
Tree 2 & 0.17 & 0.16 & $4.98 \%$ \\
Tree 3 & 0.28 & 0.27 & $4.13 \%$ \\
Tree 4 & 0.18 & 0.17 & $5.80 \%$ \\
Tree 5 & 0.19 & 0.18 & $6.65 \%$ \\
Tree 6 & 0.39 & 0.4 & $2.72 \%$ \\
(Teak) & & & \\
\hline
\end{tabular}

\section{Conclusion}

On the basis of this study, the conclusion has been made that the developed software system
Table 2: Contrast table for standing tree height with two different methods

\begin{tabular}{llll}
\hline $\begin{array}{l}\text { Tested } \\
\text { Trees }\end{array}$ & $\begin{array}{l}\text { Height }(\mathbf{m}) \\
\text { (Proposed } \\
\text { Method) }\end{array}$ & $\begin{array}{l}\text { Height }(\mathrm{m}) \\
\text { (Experimental } \\
\text { Values) }\end{array}$ & $\begin{array}{c}\text { Percentage } \\
\text { Error }\end{array}$ \\
\hline Tree 1 & 7.56 & 7.52 & \\
Tree 2 & 7.41 & 7.39 & $0.53 \%$ \\
Tree 3 & 7.6 & 7.57 & $0.27 \%$ \\
Tree 4 & 7.3 & 7.26 & $0.40 \%$ \\
Tree 5 & 7.42 & 7.4 & $0.55 \%$ \\
Tree 6 & 5.83 & 6.13 & $0.27 \%$ \\
(Teak) & & & $4.90 \%$ \\
\hline
\end{tabular}

gave estimation of woody volume of a live tree through image capturing, processing and analyzing approach. The developed software application is free from the camera position and recognizes three parameters (Height, Diameter (at breast height) and volume) of the selected six sample of tree. Parameters were calculated after executing the basic functions of digital image processing. The percentage error of calculating different parameters of trees between proposed method and experimental analysis is found to be less than $6.65 \%$.

\section{References}

1. Chaithanya $C$ and Priya $S$, Object Weight Estimation From 2D Images. ARPN J Engg and Appl Sci. vol.10(17), pp.7574-78 (2015).

2. Dean C. Calculation of Wood Volume and Stem Taper Using Terrestrial SingleImage Close- Range Photogrammetry and Contemporary Software Tools. Silval Fenn vol.37(3), pp.359-80 (2003).

3. Garg D K, Thakur D, Sharma S and Bhardwaj S. ECG Paper Records Digitization through Image Processing Techniques. Int J Comp Appl. vol.48(13), pp.35-38 (2012).

4. Ghasemi N, Sahebi M R and Mohammad zadeh A. A review on biomass estimation methods using synthetic aperture radar data. Int J Geomatics and Geosci. vol.1(4), pp.776-88 (2011).

5. Jusoff H K. Estimating Acacia Mangium Plantation's Standing Timber Volume Using an Airborne Hyperspectral Imaging System. Open Forest Sci J. vol.1, pp.61-67 (2008).

6. Kaur $S$ and Singh D. Geometric Feature Extraction of Selected Rice Grains using Image Processing Techniques. Int J of Comp Appl. vol.124(8), pp.41-46 (2015).

7. Lu D, Chen $Q$, Wang $Q$, Liu L, Li G and Moran E. A survey of remote sensing-based 
aboveground biomass estimation methods in forest ecosystems. Int J Digital Earth. vol.9(1), pp.63-105 (2014).

8. Mishra A, Asthana $P$ and Khanna P. The Quality Identification of Fruits in Image Processing Using MATLAB. Int J Res Engg and Technol. vol.3(10), pp.92-95 (2014).

9. Parmar D K, Ghodasara Y R, Patel K P, Patel $K V$ and Kathiriya $D$ R. Estimation of Plant Leaf Area using Java Image Processing Techniques. Int $J R e$ and Innov Trends Computing and Comm. vol.3(2), pp.848-51 (2015).
10. Patil S B and Bodhe S K. Image Processing Method to Measure Sugarcane Leaf Area. Int J Engg Processing. ARPN J Agril and Biol Sci. vol.2(6), pp.17-22 (2011).

11. Sabliov C M, Boldor D, Keener K M and Farkas B E. Image Processing Method to Determine Surface Area and Volume of AxiSymmetric Agriculture Products. Int J Food Properties. vol.5(3), pp.641-53 (2002).

12. Sharma S, Singh D and Chauhan S. An interactive computer vision system for tree ring analysis. Current Sci. vol.112(6), pp.1262-65 (2017). 